\title{
Social welfare effects of tax-benefit reform under endogenous participation and unemployment: an ordinal approach
}

\author{
Brigitte van Baalen • Tobias Müller
}

Published online: 11 January 2013

(C) Springer Science+Business Media New York 2013

\begin{abstract}
This paper analyzes the social welfare effects of tax-benefit reforms in a framework integrating endogenous labor supply and unemployment. We adopt an ordinal approach to social welfare comparisons by searching for "socially desirable" reforms that would improve social welfare for an entire class of social welfare functions. In the model, there is a discrete distribution of individuals' productivities and individuals are heterogeneous with respect to leisure preferences (or disability of work). Labor supply decisions are limited to the participation decision. Unemployment is modeled in a search and matching framework with individual wage bargaining. For the social welfare analysis, the model is calibrated for Switzerland. Starting from a situation with an unemployment benefit scheme, the introduction of in-work benefits is shown to be a "socially desirable" reform: it would be unanimously preferred to the current situation according to all social welfare functions based on the criteria of Pareto, anonymity, and the principle of transfers. This result holds for two different types of preference heterogeneity (leisure preferences or disability of work) and also for the case where job search effort cannot be monitored.
\end{abstract}

Keywords Tax-benefit reform $\cdot$ Unemployment $\cdot$ Search-matching models $\cdot$ Social welfare $\cdot$ Preference heterogeneity

Support by the Swiss National Science Foundation (Grant No. 4045-59741, National Research Programme 45: "Future Problems of the Welfare State") is gratefully acknowledged.

Electronic supplementary material The online version of this article

(doi:10.1007/s10797-012-9263-7) contains supplementary material, which is available to authorized users.

B. van Baalen

Swiss Federal Tax Administration, Schwarztorstrasse 50, 3003 Berne, Switzerland

e-mail: Brigitte.vanBaalen@estv.admin.ch

T. Müller $(\varangle)$

Department of Economics, University of Geneva, 40 boul. du Pont-d'Arve, 1211 Geneva 4,

Switzerland

e-mail: Tobias.Mueller@unige.ch 
JEL Classification D63 $\cdot$ H21 $\cdot$ J64

\section{Introduction}

The persistence of unemployment and the appearance of new types of poverty in Europe has raised the awareness of the link between the tax system, unemployment insurance, and social assistance. In this context, incentive problems-such as the possible existence of a poverty or unemployment trap-have become more prominent. As governments face increasing difficulties to finance the social transfer system, the introduction of tax credits or other reforms of the tax-benefit system are widely discussed, but their implementation meets with resistance in most continental European countries.

The economic consequences of reform proposals have traditionally been analyzed in a competitive labor market setting, focusing on labor supply response (see, e.g., Moffitt 2003; Fortin et al. 1993; Blundell et al. 2000). In this context, as in the optimal taxation literature originated by Mirrlees (1971), redistribution implies necessarily a trade-off between equity and efficiency. A more equitable distribution of income can only be obtained at the expense of reduced aggregate output. The exclusive reliance on labor supply response can, however, be misleading. An ill-conceived reform of the tax-benefit system might have the unwanted side effect of increasing involuntary unemployment. To avoid unwarranted conclusions, it is crucial to take labor market imperfections into account in the analysis of tax-benefit reforms. In such a framework, more redistribution does not necessarily come at the expense of economic efficiency.

This paper analyzes the effects of tax-benefit reforms in a framework integrating endogenous labor supply and unemployment. We use a search-matching model of labor markets with endogenous participation and heterogeneity in two dimensions: individual productivity (skill) and preference for leisure. Combining theoretical considerations and simulation analysis for the Swiss case, we address the question whether there are reforms leading to outcomes that are socially preferred to the current situation where an unemployment insurance system is in place. To ensure comparability, reforms are required to be neutral with respect to the government budget.

What criterion should be used to determine whether a reform is socially desirable? As most reforms produce winners and losers, the Pareto criterion is of little use for ranking pre- and post-reform situations. In order to overcome the incompleteness of Pareto rankings, many economists resort to social welfare functions, which rely on interpersonal comparisons of well-being. As the choice of a specific social welfare function reflects an observer's value judgments, its use in the evaluation of policy reforms might be criticized for its subjectivity. This weakness can, however, be addressed by carrying out comparisons of pre- and post-reform income distributions for an entire class of social welfare functions. By performing such ordinal comparisons of income distributions, unanimous judgments on the desirability of a reform can be obtained. This is the approach we follow in our paper.

We label a policy reform as socially desirable if the post-reform situation dominates the current situation in terms of social welfare. This terminology is motivated by the fact that all observers whose ethical preferences are characterized by a social welfare function of a given class would support such a reform. In our search 
for socially desirable policy reforms, we concentrate on second-order social welfare dominance. That is, we are evaluating the desirability of a reform with respect to the class of social welfare functions that embody some degree of inequality aversion.

Necessary conditions for a reform to be socially desirable are that economic efficiency is improved and that the poorest individual's utility does not deteriorate. ${ }^{1}$ The latter condition excludes as possible reform candidates a simple reduction in unemployment benefits. There is, however, scope for enhancing efficiency without worsening the situation of the least well-off. In models of involuntary unemployment, a more progressive tax structure might reduce unemployment and improve overall economic efficiency (Pissarides 1998; Sørensen 1999; Strand 2002).

These results are based on models where labor supply is exogenous and individual heterogeneity is not taken into account. They are at odds with the optimal taxation literature which focuses on skill heterogeneity and where greater equity comes at the expense of efficiency. In order to build a bridge between these approaches, our framework integrates endogenous labor supply decisions into a search-matching model of unemployment, akin to Hungerbühler et al. (2006) and Lehmann et al. (2011). As in recent models of optimal taxation, we assume that there is a discrete distribution of individuals' productivities (Saez 2002) and that individuals are heterogeneous with respect to preferences for leisure (Beaudry et al. 2009) or disutility of labor (Choné and Laroque 2005, 2011). In our model, labor supply decisions consist in deciding whether to participate or not; individuals cannot choose the number of hours they would like to work. This simplifying assumption is motivated by the fact that elasticities of hours of work conditional on participating are found to be small in most empirical studies (Blundell and MaCurdy 1999).

Unemployment is modeled in a search and matching framework with individual wage bargaining, following Pissarides (2000). We assume that different skill levels are perfect substitutes in production. To allow a consistent evaluation of welfare effects, transitions toward the steady state are explicitly taken into account and social welfare evaluations are based on individuals' intertemporal utilities. To the extent that the impact of policy changes on social welfare has an ambiguous sign, we calibrate the model using data for Switzerland.

In our model, the government is able to observe an individual's skill if he is working, but not otherwise. Individual preferences are private information. We assume furthermore that the government does not know what type of preference heterogeneity underlies the observed participation behavior. Following Cuff (2000), we consider two versions of preference heterogeneity (taste for leisure or work disability), which have identical behavioral implications but yield different cardinal utilities, with important implications for interpersonal comparisons by the government.

The decision to search for a job is a binary decision in our model. We do not model explicitly the imperfect monitoring of search effort (see Van der Linden 2004), but we take this issue into account by considering two polar cases: one where job

\footnotetext{
${ }^{1}$ These necessary conditions are derived from two special cases of this class of social welfare functions (SWF): the utilitarian SWF and the Rawlsian SWF. Note also that second-order social welfare dominance does not exclude the case where a reform produces winners and losers as long as the former are on average poorer than the latter.
} 
search behavior is perfectly observed and another where it cannot be observed at all. A socially desirable reform policy must improve social welfare in both cases.

In our search for social-welfare-improving reform policies, we look for possible reform candidates in two steps. First, we explore the conditions that would ensure efficient policies, allowing for nonlinear taxation. We show that, with unemployment benefits in place, the government can implement an efficient policy only if job search can be perfectly monitored. Such a policy would require to implement in-work benefits and a marginal tax schedule that decreases with skill. Second, we explore the social welfare effects of tax-benefit reform, considering an entire class of social welfare functions and limiting our analysis to linear tax-benefit schemes.

The introduction of in-work benefits turns out to be a socially desirable reform, with unemployment benefits maintained at the current level. We confirm this result by using an ordinal approach: the post-reform distribution second-order dominates the pre-reform distribution for all versions of our model.

The remainder of the paper is organized as follows. The next section discusses the relation between our paper and the relevant literature. Section 3 describes the model. Section 4 presents the ordinal approach to policy reform and explores potential reform policies. Section 5 concludes.

\section{Relation to the literature}

The approach chosen in our paper is related to the literature on tax reform in the late seventies when Feldstein (1976) argued that it is more realistic to consider small changes from the status quo (tax reform) rather than an optimal "de novo" tax design (optimal taxation). According to Feldstein, tax reform is piecemeal and dynamic and its analysis must take the existing tax system as a starting point. In more formal contributions, Guesnerie (1977) and Weymark (1981) analyze the conditions under which a small change from the existing tax system leads to a Pareto improvement. Our approach is in the spirit of Feldstein but differs from Guesnerie's and Weymark's perspective mainly because we use a different criterion for evaluating the reform: Generalized Lorenz dominance (or second-order stochastic dominance). The reforms that we consider fulfill the conditions of second-order stochastic dominance but generally do not lead to first-order stochastic dominance of the post-reform over the pre-reform utility distribution. These reforms are not Pareto-improving because highskill workers lose with the introduction of an in-work benefit that is accompanied by higher marginal tax rates, and overall a more progressive tax system.

There are obvious links between our paper and the vast literature on optimal taxation although our paper asks a different question. The optimal taxation approach describes the optimal tax-benefit scheme for a given social welfare function whereas we are searching for reforms that might improve social welfare compared to the current (nonoptimal) situation, for an entire class of social welfare functions. The latter (ordinal) approach imposes much more stringent conditions on the choice of desirable reform policies than the use of a single social welfare function would imply. ${ }^{2}$

\footnotetext{
${ }^{2}$ If the desirability of reforms were evaluated using a single social welfare function, a loss in efficiency could always be traded off against a reduction in inequality and a decrease in the poorest individual's
} 
One strand of the optimal taxation literature focuses on labor supply models without search frictions. Our paper is related in particular with contributions that concentrate on the extensive margin of labor supply. Our way of modeling labor supply decisions is similar to Diamond (1980) and the "extensive responses" model in Saez (2002) where individuals are heterogeneous with respect to their productivity and utility from leisure (or disutility from work) and the skills of workers are observable because individuals can only work full-time in a job that corresponds to their skill. As Saez (2002, p. 1050) shows, social welfare generally increases if one moves from a negative income tax (NIT) toward an Earned Income Tax Credit (EITC) schedule. However, this result does not hold if the social welfare function (SWF) is utilitarian or of the Rawlsian type. Therefore, the extensive model of labor supply seems to favor the introduction of in-work benefits, but not under all SWF that are part of the class that we consider. ${ }^{3}$ In our model, the introduction of in-work benefits tends to be more favorable than in these contributions because of the moderating influence of these benefits (and the higher marginal tax rate that accompanies them) on the wage bargaining process.

We take also account of the important insight by Cuff (2000) that the type of preference heterogeneity matters for the definition of cardinal utilities (and social welfare) even if observable behavior is the same. For example, if participation decisions are determined by heterogeneous preferences for leisure, the inactive are generally better off than similarly skilled individuals who participate in the labor market. On the other hand, if there is heterogeneity in disutility from participating in the labor market, working individuals are generally better off than the inactive. ${ }^{4}$

More recently, search frictions and unemployment have been taken into account in the analysis of optimal taxation. Our paper is related to Boone and Bovenberg (2002, 2004), Hungerbühler et al. (2006), and Lehmann et al. (2011) who take account of the existence of involuntary unemployment in their analysis of optimal taxation. In contrast to these contributions, our analysis relies on a dynamic version of the Pissarides (2000) model whereas Hungerbühler et al. (2006) and Lehmann et al. (2011) use a static version of this model and Boone and Bovenberg (2004) formulate a static model of search unemployment with linear search costs. The dynamic framework is important in our context since we want to account for the transition from the prereform to the post-reform situation. The transition path is crucial for a consistent evaluation of changes in individual welfare.

Boone and Bovenberg (2004) and Hungerbühler et al. (2006) rely on a formulation of labor supply where individuals are heterogeneous with respect to their productivity or skill. We assume not only heterogeneity in productivity but also with respect to the preference for leisure, similar to Lehmann et al. (2011). Interestingly, these authors

welfare could always be traded off against an increase in the welfare of other individuals. Our main resultthat the introduction of in-work benefits leads to a situation which dominates the current situation in terms of social welfare-cannot be inferred from the description of optimal tax schedules.

${ }^{3}$ In a model with discrete participation decisions and a continuous effort level, Choné and Laroque (2011) show that financial incentives to work for low-skill individuals are part of the optimal tax schedule when participation costs are pecuniary. See also Beaudry et al. (2009) for a similar contribution in a different setup (discrete productivities).

${ }^{4}$ See also Choné and Laroque (2010) for a rigorous analysis of this question in the Mirrlees model. 
find that the optimal tax schedule includes an EITC-type in-work benefit if the social welfare function is close to the utilitarian case, but resembles a NIT if the SWF is of the Rawlsian type.

Finally, there are a few other contributions in the literature that analyze the effects of tax-benefit reforms in a labor market with frictions. Our paper differs from these contributions by carrying out an ordinal welfare analysis, on the one hand, and by combining an endogenous participation decision with heterogeneous skills and unemployment. In our view, all these elements are crucial for the analysis of tax-benefit reform; other contributions have considered only a subset. For example, Van der Linden (2002) analyzes the introduction of a basic income in a framework with union bargaining, risk-averse workers and exogenous labor supply; Van der Linden (2004) endogenizes the participation decision, but does not capture skill heterogeneity and neglects the dynamic adjustment path. ${ }^{5}$

\section{The model}

As we want to sort out the implications of possible reform policies, it is important to give an accurate definition of the pre-reform situation, on the one hand, and to define clearly the policy instruments that are available for reform, on the other hand. We try to capture the current situation in Switzerland (and other continental European countries) by assuming that the existing tax-benefit system is characterized by the existence of an unemployment insurance scheme, but that no help is provided by the government to individuals who are not actively seeking for work. Unemployment benefits are financed by a tax on labor earnings. By contrast to the situation in the US and the UK, no Earned Income Tax Credit (EITC) or Working Tax Credit (WTC) exists in the initial situation.

As to policy instruments, we assume that the government's action is constrained by the impossibility to observe an individual's preference for leisure (or disutility of work). Moreover, an individual's skill cannot be observed if he is not working. Therefore, the government is unable to differentiate benefits paid to those who do not hold a job. By contrast, an individual's skill can be observed if he is working: this is ensured by the assumption that individuals can only work full-time in a job that matches their skill.

The payment of unemployment benefits gives rise to a moral hazard problem if individuals outside the labor force do not receive any benefits. As the government is unable to determine an unemployed's type, it does not know whether an individual has a real incentive to search for work (job search is a binary decision in our model). ${ }^{6}$ Therefore, it makes sense for the government to monitor search effort of unemployed individuals. We do not model imperfect monitoring explicitly ${ }^{7}$ but we take this is-

\footnotetext{
${ }^{5}$ See also Lehmann (2003) who analyzes the introduction of a basic income in a search-matching model with two skill categories and exogenous labor supply.

${ }^{6}$ In a first-best world where it observes individuals' types (skill and preference parameters), an inequalityaverse government would choose a policy that would equalize utility levels of all individuals (Choné and Laroque 2005). Those who have a strong taste for leisure would be taxed whereas the government would pay an unemployment benefit only to those whose preference for leisure is below a certain threshold.

${ }^{7}$ Calibration of monitoring parameters would be somehow arbitrary.
} 
sue into account by considering two polar cases: one where job search behavior is perfectly observed and another where it cannot be observed.

Reform policies are further constrained by the government's ignorance about the type of preference heterogeneity that underlies the observed participation behavior. We consider two types of heterogeneity (heterogeneous preferences for leisure or heterogeneous disutility of work) that give rise to the same observed labor market behavior. As the government is unable to determine the type of heterogeneity that governs economic behavior, a socially desirable reform policy must improve social welfare in both types of models.

The policy instruments at the disposal of the government are the following benefits and taxes that depend on the labor market status of the individual. ${ }^{8}$ For individuals who are not working, we denote unemployment benefits by $z_{u}$ and benefits paid to individuals outside the labor force by $z_{n}$. We distinguish two polar cases: (i) if perfect monitoring of job search is possible, the two can be fixed independently and (ii) if search monitoring is impossible, the two must be equal $\left(z_{n}=z_{u}\right)$. As the government is able to observe the skill $i$ of individuals who are working, in-work benefits can be differentiated by skill and are denoted by $z_{w i}$. Marginal tax rates on (net) wage income can also be differentiated by skill and are denoted by $\tau_{i}$. Note that all these instruments are linked by the government's intertemporal budget constraint. ${ }^{9}$

\subsection{Employment, unemployment, and participation}

We assume that there is a finite number of skill levels and that productivity $p_{i}$ of a worker with skill level $i$ can be perfectly observed by firms. Each firm employs one worker and produces an identical homogeneous good whose price is the numéraire. ${ }^{10}$ In this setup, labor markets for different skill levels would operate independently from each other if there was no government intervention; redistributive policies constitute the only link between these markets.

The labor market for each skill level is modeled following a standard searchmatching framework (Pissarides 2000). Individuals are assumed to be risk neutral. Let $u_{i}$ denote the unemployment rate and $v_{i}$ vacant jobs as a fraction of the labor force with skill level $i$. The process by which job vacancies and unemployed workers are matched is represented by a matching function $M\left(u_{i}, v_{i}\right)$, which is assumed increasing in both arguments, concave and homogeneous of degree 1 . For simplicity, $M$ is identical for all skill levels. The probability of matching a vacant job to an unemployed worker per unit time is given by $M\left(u_{i}, v_{i}\right) / v_{i}=M\left(u_{i} / v_{i}, 1\right)=M\left(1 / \theta_{i}, 1\right)=$ $m\left(\theta_{i}\right)$ where $\theta_{i}=v_{i} / u_{i}$ measures tightness of the labor market for skill level $i$.

\footnotetext{
${ }^{8}$ Because of the absence of capital in the model, we adopt the conservative assumption that there is no tax on firm profits. The entrepreneurs' income could be taxed away without creating distortions in our model, but such an outcome would be unrealistic. Indeed, in a more complete model with capital accumulation, a tax on profits would have detrimental effects on growth.

${ }^{9}$ In our simulations of Sects. 4.2 and 4.3, we assume that the marginal tax rate is unique and independent of skill. For given benefits, the marginal tax rate on labor income is then determined by the government's intertemporal budget constraint.

${ }^{10}$ This assumption is analogous to the hypothesis, which is standard in the literature of optimal taxation, that different labor types are perfectly substitutable.
} 
As the dynamic analysis will show, it is easier to express the model in terms of the employment rate (the share of employed individuals in total population), $\ell_{i}$, rather than the unemployment rate. The two are related by $\ell_{i}=\left(1-u_{i}\right) \pi_{i}$, where $\pi_{i}$ denotes the participation rate. The employment rate $\ell_{i}$ evolves according to

$$
\dot{\ell}_{i}=\theta_{i} m\left(\theta_{i}\right)\left(\pi_{i}-\ell_{i}\right)-q \ell_{i} .
$$

The first term on the right-hand side denotes the transition of the unemployed, $\left(\pi_{i}-\ell_{i}\right)$, toward employment, where $\theta_{i} m\left(\theta_{i}\right)$ is the probability per unit time that an unemployed finds a job. The second term represents those who are leaving employment because their job is destroyed ( $q$ is the exogenous probability of job destruction per unit time, identical for all $i$ ).

Consider now the present discounted value of expected profits from a vacant job, $V_{i}$, and from an occupied job, $J_{i}$. The Bellman equation for $V_{i}$ is

$$
r V_{i}=-p_{i} c+m\left(\theta_{i}\right)\left(J_{i}-V_{i}\right)+\dot{V}_{i},
$$

where $c$ is the cost of maintaining a job vacant. The zero-profit condition implies that $V_{i}=\dot{V}_{i}=0$ such that

$$
J_{i}=p_{i} c / m\left(\theta_{i}\right)
$$

holds at any moment in time. Moreover, $J_{i}$ evolves according to

$$
r J_{i}=p_{i}-w_{i}\left(1+\tau_{i}\right)-q\left(J_{i}-V_{i}\right)+\dot{J}_{i},
$$

where $w_{i}$ is the wage (net of tax).

The present discounted value of an unemployed worker's expected future income, $U_{i}$, evolves according to

$$
r U_{i}=z_{u}+\theta_{i} m\left(\theta_{i}\right)\left(W_{i}-U_{i}\right)+\dot{U}_{i},
$$

whereas for employed workers the corresponding value is $W_{i}$ and follows

$$
r W_{i}=w_{i}+z_{w i}+q\left(U_{i}-W_{i}\right)+\dot{W}_{i} .
$$

After a vacant job has been occupied by an unemployed worker, the wage is determined by bilateral wage bargaining. Thus, the wage is obtained as the solution to the generalized Nash maximand

$$
\max _{w_{i}}\left(W_{i}-U_{i}\right)^{\beta}\left(J_{i}-V_{i}\right)^{1-\beta},
$$

where $\beta$ represents the worker's relative bargaining power. Assuming that wages are continually renegotiated implies that the necessary condition

$$
\beta\left(J_{i}-V_{i}\right)=(1-\beta)\left(1+\tau_{i}\right)\left(W_{i}-U_{i}\right)
$$

holds not only in levels and but also in rates of change. After some manipulation (see, e.g., Pissarides 2000), the following wage equation is obtained:

$$
w_{i}=(1-\beta)\left(z_{u}-z_{w i}\right)+\frac{\beta p_{i}}{1+\tau_{i}}\left(1+\theta_{i} c\right) .
$$


Net wages are a weighted average of the worker's fallback position and the net output that the worker produces on his job (including the saving of hiring costs enjoyed by the firm). The latter term depends on the worker's skill level $p_{i}$ and on his bargaining power: the higher his bargaining power, the greater his share of net output.

We model the participation decision in two different ways, which differ in the manner individual heterogeneity is taken into account. Here, we present a first version of the model (with heterogeneity in preferences for leisure) and defer the description of the other version to the next subsection. Individuals who stay outside the labor force receive a real return from leisure of $x$ per unit of time, in addition to any monetary transfer paid by the government. The present discounted value of such an individual's utility (measured in real monetary units), $N(x)$, is therefore given by

$$
r N(x)=x+z_{n} \text {. }
$$

Individuals of a given skill level are all equally productive on their jobs, but heterogeneous with respect to their preference for leisure. This heterogeneity is described by a distribution function $H(x)$, which is common to all skill levels. Individuals for whom $N(x)<U_{i}$ choose to work. The reservation level $\xi_{i}$ of the leisure parameter $x$ (i.e. the value at which an individual of skill $i$ is indifferent between leisure and work) is determined implicitly by the arbitrage condition $N\left(\xi_{i}\right)=U_{i}$ and is therefore equal to

$$
\xi_{i}=\frac{(r+q)\left(z_{u}-z_{n}\right)+\theta_{i} m\left(\theta_{i}\right)\left(w+z_{w i}-z_{n}\right)}{r+q+\theta_{i} m\left(\theta_{i}\right)} .
$$

Finally, the fraction of the population who choose to work (or to look for work) is equal to $\pi_{i}=H\left(\xi_{i}\right)$.

The government's budget constraint constitutes the only link between labor market segments (corresponding to skill levels). We require that the intertemporal budget constraint be satisfied across segments, but the budget does not have to be balanced in each period. We assume that the marginal tax rates $\tau_{i}$ are constant over time. Their levels are set such as to balance the intertemporal budget constraint.

It useful to break down the government's net borrowing by labor market segment

$$
\dot{b}_{i}=r b_{i}+\left(\pi_{i}-\ell_{i}\right) z_{u}+\ell_{i} z_{w i}+\left(1-\pi_{i}\right) z_{n}-\ell_{i} \tau_{i} w_{i},
$$

where $b_{i}$ is per capita borrowing by the government related to skill level $i$. Integrating equation (12) and imposing the no-Ponzi condition yields

$$
b_{i}(0)=\int_{0}^{\infty}\left[\ell_{i} \tau_{i} w_{i}-\left(\pi_{i}-\ell_{i}\right) z_{u}-\ell_{i} z_{w i}-\left(1-\pi_{i}\right) z_{n}\right] \mathrm{e}^{-r t} \mathrm{~d} t .
$$

This equation makes clear that $b_{i}(0)$ is the present value of future net contributions of skill $i$ to the government budget. The initial values of $b_{i}$ indicate the degree of redistribution among skill levels. A positive (negative) value of $b_{i}(0)$ indicates that individuals of skill $i$ are net tax payers (net tax beneficiaries) in present value terms.

The initial stock of total government borrowing is set to zero. Therefore, the government's intertemporal budget constraint can be written as

$$
b(0)=\sum_{i} s_{i} b_{i}(0)=0,
$$

where $s_{i}$ is the share of workers with skill $i$. 
We assume that the levels of per capita transfers $\left(z_{u}, z_{w i}\right.$ and $\left.z_{n}\right)$ and the tax rate on labor income $\left(\tau_{i}\right)$ are constant over time. The government chooses the levels of these variables such as to balance the intertemporal budget constraint (14), anticipating thereby the future evolution of the economy.

The dynamics of the model can now be made explicit. Substituting Eq. (9) into (4) establishes, together with (3), that both $J_{i}$ and $\theta_{i}$ are constant over time, i.e., they jump instantaneously to their equilibrium value. The same is true for the variables $U_{i}$ and $W_{i}$, since differential equations (5) and (6) are unstable. ${ }^{11}$ The only variable that does not adjust immediately to its steady-state level is the employment rate (because of the forward-looking behavior of the government, all fiscal variables are assumed to be constant over time).

The equilibrium of the model can thus be summarized as follows. Consider first the determination of labor market tightness and the wage rate. Combining Eqs. (3) and (4) yields the "job creation" condition:

$$
w_{i}=\frac{p_{i}}{1+\tau_{i}}\left[1-\frac{c(r+q)}{m\left(\theta_{i}\right)}\right] .
$$

For each skill level, the wage curve (9) and the job creation condition (15) determine jointly the equilibrium level of $\theta_{i}$, for a given tax rate $\tau_{i}$, as follows:

$$
(1-\beta)\left[p_{i}-\left(1+\tau_{i}\right)\left(z_{u}-z_{w i}\right)\right]=\left[r+q+\beta \theta_{i} m\left(\theta_{i}\right)\right] p_{i} c / m\left(\theta_{i}\right) .
$$

As $\tau_{i}$ is determined using the intertemporal budget constraint of the government (14), each $\theta_{i}$ depends in general on the levels of participation rates and on the path of the employment rates in all labor market segments. There is, however, one particular set of policies which breaks the interdependence between the levels of labor market tightness in the different labor market segments. Indeed, it is obvious from (16) that the tax rate has no incidence on the determination of $\theta_{i}$ if the condition $z_{u}=z_{w i}$ is satisfied. Equation (16) allows even a stronger conclusion: any policy reform, which satisfies the condition $z_{u}=z_{w i}$ leaves labor market tightness unchanged for all skill levels.

Turn now to the determination of the rates of participation, employment, and unemployment. It should be emphasized that, on the one hand, the unemployment rate does not adjust immediately to its long-run level and, on the other hand, the initial unemployment rate is not fixed. Indeed, as Eq. (11) reveals, the participation rate $\pi$ jumps immediately to its equilibrium value after a shock. As a consequence, individuals who choose to participate must queue for jobs, increasing thereby the initial unemployment rate. ${ }^{12}$ This argument makes clear that in the model with endogenous

${ }^{11}$ Note that, because of wage bargaining, the difference $W_{i}-U_{i}$ depends only on $\theta_{i}$. Indeed, Eqs. (3) and (8) imply

$$
W_{i}-U_{i}=\left(\frac{\beta}{1-\beta}\right) \frac{p_{i} c}{\left(1+\tau_{i}\right) m\left(\theta_{i}\right)} .
$$

${ }^{12}$ Alternatively, if a shock decreases the participation rate, some of the unemployed will quit the queue, thereby decreasing the unemployment rate. 
participation, the "sticky" variable is not the unemployment rate, but the employment rate, $\ell_{i}$.

The evaluation of policy reforms carried out below rely on social welfare functions that are built on the assumption that interpersonal comparisons of utility levels are possible. It is therefore important to define individual utility levels in a consistent way. This can be ensured by measuring utility levels in a money metric and by choosing the initial utility level (at time $t=0$ ) as the pertinent indicator for the assessment of policy reforms. Indeed, the initial utility level can be interpreted as the "asset value" of being in a certain state (employment, unemployment, etc.) and summarizes the present value of expected future income. This is why we use the dynamic formulation of the model in our analysis; the steady-state equations would not allow to obtain correct measures of individual utilities.

When using social welfare measures which are sensitive to distributional considerations, the structure of firm ownership matters. To keep things transparent, we assume that there is a homogeneous group of entrepreneurs whose only income stems from entrepreneurial activity, i.e. profits from occupied jobs. It would not be realistic to assume that each entrepreneur owns exactly one firm (they would be the poorest population group); we assume instead that all entrepreneurs share equally the ownership of all firms.

\subsection{Preference heterogeneity: alternative interpretations}

In the model outlined above, an individual outside the labor force receives a real return to leisure of $x$ (and a transfer $z_{n}$ ). In this version of the model, those who have a strong taste for leisure decide to stay outside the labor force. From the point of view of the government who measures individual utilities in cardinal terms, these inactive individuals are better off than the unemployed of the same skill. ${ }^{13}$ Due to their high utility level, inactive individuals receive a smaller weight in a social welfare function that embodies a preference for equality. In this context, the government interprets a strong taste for leisure as a form of "laziness" on the part of those individuals (Cuff 2000).

Following Cuff's (2000) original idea, the model can be reformulated in a way that yields an identical outcome in terms of all observable variables but a different set of individual cardinal utilities. In this alternative version of the model, we assume that the real return to leisure is identical for all individuals $(v)$, but that there is heterogeneity in disutility from participating in the labor market. ${ }^{14}$

As above, the heterogeneity parameter is denoted by $x$ and is distributed according to the distribution function $H(x)$. The newly defined utility levels are denoted by a

\footnotetext{
${ }^{13}$ Most inactive individuals are also better off than most of the working individuals of the same skill. In the model, the utility of being employed is higher than the utility of being unemployed, but this difference is rather small due to the fast turnover in the labor market.

${ }^{14}$ The equivalence between the two versions of the model holds only if individuals experience the same level of disutility from being employed and from being unemployed. This assumption might seem strong, but can be justified by the fact that it is not necessarily easier for a disabled person to actively seek for work than to be employed.
} 
tilde and are related to the original utility levels as follows:

$$
\begin{aligned}
\tilde{U}_{i}(x) & =U_{i}+(v-x) / r, \\
\tilde{W}_{i}(x) & =W_{i}+(v-x) / r, \\
\tilde{N} & =N(x)+(v-x) / r=\left(v+z_{n}\right) / r .
\end{aligned}
$$

An individual characterized by skill $i$ and work disutility $x$ decides to participate in the labor market if his work disutility is smaller than a critical level $\xi_{i}$, which is defined by $\tilde{U}_{i}\left(\xi_{i}\right)=\tilde{N}$. It is straightforward to show that this reparameterization of the model leads to identical outcomes in all observable variables. The intuitive reason for this result is that what matters for individuals who participate in the labor market is the difference between their utility levels when employed and when unemployed; this difference is the same in both versions of the model.

However, the distribution of cardinal utilities is different from the original version of the model. Here, individuals outside the labor force are less well-off than those who are in the labor force. Therefore, the weights of inactive individuals in the social welfare function are greater than the weights of those who are in the labor force. The government sees the former as the neediest since they have the greatest disability for work. This interpretation of the parameter $x$ as a form of disability has therefore very different implications for social welfare compared to the original version of the model where $x$ can be interpreted as a form of laziness.

In the remainder of the paper, we will refer to the original version of the model as $L$-model (or $L$-heterogeneity) where $L$ stands for leisure or laziness. The modified model will be referred to as $D$-model (or $D$-heterogeneity) where $D$ stands for disutility from work or disability.

\subsection{Calibration of the model}

When evaluating the social welfare consequences of different reform programs, it is not always possible to get clear-cut qualitative results. Nevertheless, quantitative conclusions can be drawn by calibrating the model and by simulating various reform policies in our dynamic framework. The parameters of the model are chosen in such a way that the long-run equilibrium of the model replicates the main labor market indicators of the Swiss economy in 1998 (see Tables 1 and 2). ${ }^{15}$ The model is calibrated in two steps. First, we calibrate an aggregate version of the model using the information contained in Table 1. Second, we calibrate productivities (differentiated by skill) that are consistent with the observed wage structure.

The matching technology is specified as a constant-returns-to-scale CobbDouglas function: $m(\theta)=m_{0} \theta^{-\eta}$. As a consequence, the matching elastiticy, $\eta$, is constant. In their survey of the matching function, Petrongolo and Pissarides (2001) report that most empirical studies do not reject the assumption of constant returns to scale and that most estimates of $\eta$ lie in the range [0.5-0.7]. As most authors of simulation studies, we choose the symmetric specification with $\eta=0.5$. Together with

\footnotetext{
${ }^{15}$ There have been very small changes in unemployment rates and the structure of wages between 1998 and 2008 in Switzerland, by contrast to other European countries.
} 
Table 1 Calibration of the model: aggregate indicators

Parameter or variable (base values) ${ }^{\mathrm{a}}$

Unemployment rate

$\pi$

0.039

Participation rate

0.83

Semi-elasticity of participation

Labor market tightness

0.239

Replacement rate

$\theta$

0.40

Job destruction rate ${ }^{b}$

$z_{u} / w$

0.077

Real interest rate $\mathrm{b}^{\mathrm{b}}$

Workers' bargaining power

$r$

Matching function (elasticity)

Cost of vacant job ${ }^{c}$

Matching function (scale parameter) ${ }^{\mathrm{C}}$

Initial tax rate e,d $^{\mathrm{d}}$

a Data sources: unemployment (OFS 2001a, p.152), participation (OFS 2001b, tableau 1a*; reference population: 15 years-retirement), vacancies (OFS 2000, p. 34), job destruction (anual mean from Flückiger and Vassiliev 2002)

${ }^{\mathrm{b}}$ Annual basis

${ }^{\mathrm{c}}$ Calibrated using the equations of the model

${ }^{\mathrm{d}}$ This value corresponds to the model with perfect monitoring of search behavior $\left(z_{n}=0\right)$. If monitoring is impossible $\left(z_{n}=z_{u}\right), \tau$ is equal to 0.101

Table 2 Calibration of the model: structural indicators

\begin{tabular}{|c|c|c|c|c|c|c|}
\hline \multirow{2}{*}{$\begin{array}{l}\text { Skill level } \\
\text { Search monitoring } \\
\text { c }\end{array}$} & \multirow[t]{2}{*}{$\begin{array}{l}\text { Share in } \\
\text { population }^{a}\end{array}$} & \multirow[t]{2}{*}{$\begin{array}{l}\text { Wage } \\
\text { index }\end{array}$} & \multicolumn{2}{|c|}{$\begin{array}{l}\text { Participation } \\
\text { rate }^{\text {b }}\end{array}$} & \multicolumn{2}{|c|}{$\begin{array}{l}\text { Semi-elasticity of } \\
\text { participation }^{b}\end{array}$} \\
\hline & & & yes & no & yes & no \\
\hline University & 0.055 & 1.000 & 0.929 & 0.955 & 0.107 & 0.074 \\
\hline Superior education & 0.225 & 0.695 & 0.882 & 0.905 & 0.157 & 0.133 \\
\hline Apprenticeship & 0.460 & 0.535 & 0.836 & 0.840 & 0.195 & 0.192 \\
\hline Basic skills & 0.260 & 0.404 & 0.776 & 0.721 & 0.236 & 0.265 \\
\hline
\end{tabular}

${ }^{\text {a}}$ Estimates from the Swiss wage structure survey 1998 (OFS 1999)

${ }^{\mathrm{b}}$ Calibrated using the equations of the model

${ }^{\mathrm{c}}$ Indicates whether it is assumed for calibration that search can be perfectly monitored $\left(y e s, z_{n}=0\right)$ or that search is impossible to monitor $\left(n o, z_{n}=z_{u}\right)$

the assumption of symmetric bargaining $(\beta=0.5)$, this ensures that the decentralized equilibrium is efficient.

The model is calibrated for four skill categories, which we take to represent different education levels. Wage differentials (reported in Table 2) between skill levels are estimated on the basis of a modified Mincerian wage equation, using dummy 
variables for the four skill levels instead of a unique variable measuring years of schooling. These estimations (as well as the proportions of the different skill groups in population) are obtained from the Swiss Wage Structure Survey 1998. Note that in this survey, employers report required skill levels for each job; this indicator is linked more closely to productivity than the worker's actual education level. Productivity parameters $p_{i}$ are then calibrated such as to reproduce the structure of wages. The marginal tax rate is assumed identical for all skill levels (see Sect. 4.2).

Turn now to the participation decision. The shape of the distribution function $H(\cdot)$ determines both the rate and the elasticity of participation, for all skill levels. The participation elasticities estimated for Switzerland are rather low on average (Gerfin and Leu 2007; Abul Naga et al. 2008) ${ }^{16}$ and these elasticities tend to decrease with the level of skill (Immervoll et al. 2007; Meghir and Phillips 2008). The lognormal distribution function reproduces these features quite well. Define the semi-elasticity of participation as $E_{i}=\left(\mathrm{d} \pi_{i} / \mathrm{d} \xi_{i}\right) \xi_{i}$. Then the lognormal distribution has the following properties:

$$
\pi_{i}=\Phi\left(\frac{\log \left(\xi_{i}\right)-\mu}{\sigma}\right), \quad E_{i}=\frac{1}{\sigma} \phi\left(\frac{\log \left(\xi_{i}\right)-\mu}{\sigma}\right)
$$

where $\Phi(\cdot)$ denotes the cumulative distribution function and $\phi(\cdot)$ the density function of the standard normal distribution. Given the average rate and elasticity of participation (see Table 1), Eqs. (20) allow to calibrate the parameters $\mu$ and $\sigma$ of the lognormal distribution. When the model is calibrated for different productivity levels, as described above, participation rates and semi-elasticities differ by skill level (see Table 2).

The calibration differs also between the model versions where we assume perfect monitoring of job search behavior (the model is calibrated assuming $z_{n}=0$ ) and the versions where monitoring is assumed impossible (the model is calibrated assuming $z_{n}=z_{u}$ ). The main difference is that the calibrated tax rate differs in the two cases and therefore the structure of initial participation rates and of semi-elasticities of participation differs slightly (see Table 2). Finally, in the $D$-model the real return to leisure $v$ is set to the mean of the lognormal distribution of $x\left(v=\exp \left(\mu+\sigma^{2} / 2\right)\right)$. With this choice, the sum of individual utilities (utilitarian social welfare criterion) is the same in both versions of the model.

\section{An ordinal approach to policy reforms}

When evaluating the desirability of an economic reform, we follow the ordinal approach to social welfare: a reform is considered socially desirable if it improves social welfare for an entire class of social welfare functions (SWF). This approach allows to identify reforms that could be agreed upon by observers with different value judgments as long as these satisfy some widely accepted criteria. In this section, we first

\footnotetext{
${ }^{16}$ For example, Gerfin and Leu (2007) report for Switzerland participation elasticities of 0.36 for married women and 0 for single women, single men, and men in couples.
} 
aim at identifying potential reform candidates by applying necessary conditions for a reform to be socially desirable. In a second step, we apply the criterion of generalized Lorenz dominance in order to check whether these potential reform policies satisfy also sufficient conditions for social desirability.

We consider the class of SWF satisfying the criterion of anonymity, the Pareto criterion and the principle of transfers. ${ }^{17}$ Due to the latter principle, the SWF belonging to this class embody some degree of inequality aversion. The two polar cases of this class of SWF are the utilitarian SWF (given by the sum of individual utilities) and the Rawlsian SWF (equal to the utility of the poorest individual).

The Rawlsian and utilitarian special cases will guide us in this search since they provide necessary conditions for a reform to be socially desirable. These necessary conditions are (i) that economic efficiency (utilitarian social welfare or the sum of individual utilities) is improved by the reform and (ii) that the "poorest" individual's utility does not deteriorate.

Note that the impact of a reform on economic efficiency is identical in the $L$-model and the $D$-model. By contrast, the identity of the poorest individual (in utility terms) differs: in the $L$-model, the individual with the lowest utility level is an unemployed worker of the lowest skill, whereas in the $D$-model, the least well-off are the inactive.

\subsection{Economic efficiency}

Improving economic efficiency is a necessary condition for a reform to dominate the pre-reform situation in terms of social welfare. In order to get some intuition on the properties of our model, we first characterize optimal policies in terms of a utilitarian social welfare criterion (which does not depend on the type of preference heterogeneity assumed in the model).

This analysis of economic efficiency differs from the optimal taxation approach in two respects. First, individual utility is linear in income in our model because of the assumption of risk neutrality. Therefore, distributional issues are not taken into account (they will become important below when we consider other SWFs). Second, we focus only on redistributional and labor market policies, assuming that no general expenditures or public goods have to be financed by taxes. One of the questions that we ask in this section is whether it is possible to design a tax-benefit scheme (with positive unemployment benefits) that achieves optimal economic efficiency.

As is detailed in Appendix A, maximizing a utilitarian social welfare criterion (the sum of individual utilities) subject to a balanced government budget yields two optimality conditions. The first condition defines optimal labor market tightness, the second optimal labor market participation. The first condition does not depend on the participation rate and can be expressed in terms of the policy instruments $z_{w i}$ and $z_{u}$ (see Appendix A):

$$
\frac{\eta\left(\theta_{i}\right)-\beta}{\beta}=\frac{(1-\beta)\left(z_{u}-z_{w i}\right)}{w_{i}-(1-\beta)\left(z_{u}-z_{w i}\right)} .
$$

\footnotetext{
${ }^{17}$ The anonymity criterion is equivalent to symmetry of the SWF with respect to individual utilities. The Pareto criterion states that the SWF is weakly increasing in individual utilities. The transfer principle states that a mean-preserving equalizing transfer does not decrease social welfare. This is equivalent to saying that the SWF is S-concave (Note that S-concavity implies symmetry).
} 
It is obvious from condition (21) that an efficient level of labor market tightness can be achieved for all skill levels if (i) the Hosios (1990) condition $\eta\left(\theta_{i}\right)=\beta$ is satisfied for all $i$ and if (ii) the government chooses $z_{w i}=z_{u}$. It is well known that if condition (i) is satisfied, search externalities are internalized and the resulting equilibrium is efficient (Hosios 1990; Pissarides 2000). As we do not focus on the correction of externalities in our simulations, we assume that condition (i) is satisfied. ${ }^{18}$

Intuitively, condition (21) can be interpreted as follows. The existence of an unemployment benefit improves the worker's fallback position and enables him to negotiate a higher wage. As a result, there is less job creation, job market tightness decreases and unemployment increases relative to a laissez-faire situation. The introduction of an in-work benefit counteracts this mechanism: it makes the job more attractive relative to unemployment and, therefore, the worker settles for a lower wage in the bargaining process. If the in-work benefit is fixed at the same level than the unemployment benefit, the two offset each other exactly in the bargaining process and labor market tightness reaches the same level as in the case without government intervention.

Note that if the Hosios condition is not satisfied, condition (21) shows how to correct the labor market externality. For example, if the workers' relative bargaining power is smaller than the efficient level $(\beta<\eta)$, the government should improve the fallback position of workers by providing higher unemployment benefits than in-work benefits. Boone and Bovenberg (2002) discuss this issue in more detail. They express the interpretation of (21) in terms of marginal and average tax rates. ${ }^{19}$ If $\beta<\eta$, the average employment tax rate (which has an impact on the size of the total surplus of the match) should be increased relative to the marginal tax rate (which affects the worker's effective bargaining power through his share of the surplus). This can be achieved, for example, by increasing unemployment benefits.

Consider now the optimal choice of labor market participation. Substituting the optimal participation condition into the government's net borrowing, Eq. (12) yields the condition (see Appendix A):

$$
z_{n}=\frac{r \ell_{i}(0)}{r \ell_{i}(0)+\theta_{i} m\left(\theta_{i}\right)} z_{u}-\frac{\theta_{i} m\left(\theta_{i}\right)}{r \ell_{i}(0)+\theta_{i} m\left(\theta_{i}\right)} r b_{i}(0) .
$$

To interpret this condition, we have to distinguish the two polar cases regarding the possibility of job search monitoring. Consider first the case of perfect monitoring where $z_{u}$ and $z_{n}$ can be differentiated. Combining (22) with the government's budget constraint (14) yields the following condition:

$$
z_{n}=\frac{\sum_{i} s_{i} \lambda_{i}}{\sum_{i} s_{i}\left(\lambda_{i}+1\right)} z_{u}, \quad \lambda_{i}=\frac{r \ell_{i}(0)}{\theta_{i} m\left(\theta_{i}\right)} .
$$

\footnotetext{
${ }^{18}$ This choice is sometimes justified by the fact that other search models lead to an equilibrium outcome where the Hosios condition is satisfied. See Moene (1997) and Mortensen and Pissarides (1999). In our simulations, we use a Cobb-Douglas matching function for which $\eta\left(\theta_{i}\right)$ is constant and identical for all skill levels.

${ }^{19}$ The difference in net tax payments between employment and unemployment is $T_{i}=\tau_{i} w_{i}-z_{w i}-z_{u}$. Define the average "employment tax rate" as $\tau_{i}^{e}=T_{i} / w_{i}$. Assuming that $\eta$ is constant, condition (21) can then be rewritten as $\bar{\tau}_{i}^{e}-\tau_{i}=(\eta-\beta) /[\eta(1-\beta)]$.
} 
The optimal marginal tax rates can be obtained by using Eqs. (12) and (22) yielding

$$
\tau_{i}=\frac{\lambda_{i}+\pi_{i}}{w_{i} \int_{0}^{\infty} r \ell_{i}(t) \mathrm{e}^{-r t} \mathrm{~d} t}\left(z_{u}-z_{n}\right) .
$$

The main result in the case with perfect search monitoring is that an optimal economic efficiency can be attained for any level of unemployment benefit if conditions (21), (23), and (24) are satisfied. These conditions define the set of efficient redistribution policies if perfect search monitoring is possible. To understand the economic intuition behind these conditions, it is useful to define the marginal and average tax rates in our model. For skill $i$, the marginal tax rate on gross wage income is $\tau_{i}^{*}=\tau_{i} /\left(1+\tau_{i}\right)$ and the average tax rate is $\bar{\tau}_{i}{ }^{*}=\tau_{i}^{*}-z_{w i} / w_{i}^{*}$, where $w_{i}^{*}=\left(1+\tau_{i}\right) w_{i}$ is the gross (before-tax) wage.

If the Hosios condition is satisfied, in-work benefits $z_{w i}$ paid to all skill levels have to be identical to the unemployment benefit, $z_{u}$. People outside the labor force receive a benefit $z_{n}$ which is proportional to $z_{u}$. Note that when Eq. (23) is evaluated using realistic parameter values, the optimal $z_{n}$ turns out to be close to zero (between $1 \%$ and $2 \%$ of the value of $z_{u}$ ). The optimal marginal tax rates are decreasing with skill according to (24) as they are (approximately) inversely proportional to the corresponding wage rates. They are set such as to ensure that average tax rates are approximately constant (and close to zero for our parameter values) for all skill levels. As a result, the marginal tax schedule is slightly higher than (but very close to) the simple tax schedule defined by $\tau_{i}=z_{u} / w_{i}$.

How can these results be interpreted? For any level of unemployment benefits, $z_{u}$, the optimal labor market tightness is obtained if in-work benefits are set at the same level, regardless of the marginal tax rates. Therefore, the marginal tax rates $\tau_{i}$ are set such as to produce no distortion on the extensive margin of labor supply (participation decision). As the participation decision depends on the average tax rate and on transfers to the inactive $z_{n}$, these policy instruments should be set such as to offset the (small) incentive to participate that is created by the unemployment benefit. In practical terms, this outcome is achieved with a small positive $z_{n}$ and average tax rates that are approximately constant and close to zero. ${ }^{20}$

Now turn to the case where job search monitoring is assumed impossible. Then we have $z_{u}=z_{n}$ and condition (22) simplifies to $z_{u}=-r b_{i}(0)$. Combining this result with the government's budget constraint yields the unambiguous result that the only efficient policy is laissez-faire where all benefits and taxes are set to zero. Therefore, the optimal situation cannot be obtained with positive unemployment benefits in

\footnotetext{
${ }^{20}$ To understand this point, it should be emphasized that any increase in $z_{w i}$ is neutral with respect to the participation decision of skill $i$ if it is offset by a budget-neutral increase in the tax rate $\tau_{i}$ : both changes apply to the same employment state and their incentive effects on participation cancel out because the average tax rate remains unchanged. The same cannot be said of unemployment assistance: $z_{u}$ is received when an individual is unemployed, but the corresponding tax is paid when the individual is working. An individual who is out of the labor force and begins to search for a job will first be unemployed before being able to find a job. Hence, the increase in unemployment benefits will be of more value for him than the fall in the net wage due to the corresponding tax increase. Therefore, a rise in $z_{u}$ tends to increase participation even if the government budget is balanced. A positive benefit paid to individuals outside the labor force, as defined in Eq. (22), counterbalances this effect.
} 
this case. Although optimal labor market tightness can still be obtained by choosing $z_{w i}=z_{u}$, the participation decision will necessarily be distorted if benefits paid to the unemployed and to the inactive cannot be differentiated.

\subsection{Social welfare}

The conditions derived in the preceding section describe the optimal policy from the point of view of an utilitarian SWF but the use of inequality-averse SWF would lead to different optimal policies. In particular, decreasing marginal tax rates would not be found optimal with a strongly inequality-averse SWF. Our focus differs from the optimal taxation perspective: we use these optimal efficiency results only as a guide to identify potential reform policies that would improve social welfare for an entire class of SWF.

Nevertheless, the set of efficient policies identified above can help us to choose potential reform policies that would be socially desirable when the initial situation is characterized by an unemployment insurance scheme with a constant marginal tax rate. From the point of view of economic efficiency, it seems reasonable to introduce in-work benefits in order to get closer to optimal labor market tightness $\left(z_{w i}=z_{u}\right)$. As in-work benefits are identical for all skill levels at the optimum, we assume that they move in parallel $\left(z_{w i}=z_{w}\right)$ even if they are below this optimal level. As to the structure of tax rates, different SWFs will find decreasing or increasing marginal tax rates optimal. Therefore, we assume for simplicity that the marginal tax rate is constant $\left(\tau_{i}=\tau\right)$. Finally, we assume in all simulations that the Hosios condition is satisfied.

In this section, we explore numerically the consequences of various reform policies on SWFs displaying different degrees of inequality aversion, ranging from the utilitarian to the Rawlsian case. Because of the convenient parameterization of inequality aversion, we choose the additive specification of the SWF proposed by Atkinson (1970). According to this specification, "equally distributed equivalent utility" $Y^{e}$ is defined as

$$
Y^{e}=\left(s_{J} Y_{J}^{1-\epsilon}+\left(1-s_{J}\right) \sum_{i, j} f_{i j}^{0} Y_{i j}^{1-\epsilon}\right)^{1 /(1-\epsilon)},
$$

where $Y_{J}$ is the utility of an entrepreneur, $i$ is the skill category, $j$ the employment state (employment, unemployment, leisure), $f_{i j}^{0}$ the share of workers of skill $i$ in state $j$ and $Y_{i j}$ the per-capita utility of those workers. For the sake of completeness, entrepreneurs are included in the welfare criterion. We assume that they represent a fixed share, $s_{J}$, of population. ${ }^{21}$ The parameter $\epsilon$ captures the degree of inequality aversion. For $\epsilon=0, Y^{e}$ measures economic efficiency and is equal to the utilitarian aggregate welfare criterion, $\Psi$. With $\epsilon \rightarrow \infty, Y^{e}$ tends toward the Rawlsian criterion where only the welfare of the poorest individual is taken into account.

\footnotetext{
${ }^{21}$ The population share $s_{J}$ is calibrated in such a way that the entrepreneur's initial utility level is twice the utility level of the average worker. The contribution of individuals outside the labor force to social welfare is not straightforward to compute because of their heterogeneity (an appendix describing the approximation procedure is available on request).
} 
Table 3 Model versions and utility levels of least well-off individuals

\begin{tabular}{|c|c|c|}
\hline \multirow[b]{2}{*}{$\begin{array}{l}\text { Model acronym } \\
\text { Least well-off individual } \\
\text { (Utility) }\end{array}$} & \multicolumn{2}{|l|}{ Possiblity of monitoring } \\
\hline & $\begin{array}{l}\text { Perfect } \\
\text { monitoring }{ }^{\mathrm{a}} \\
\left(z_{u} \neq z_{n}=0\right)\end{array}$ & $\begin{array}{l}\text { Monitoring } \\
\text { impossible }^{b} \\
\left(z_{u}=z_{n}\right)\end{array}$ \\
\hline \multicolumn{3}{|l|}{ Type of heterogeneity } \\
\hline$L$-heterogeneity & $\begin{array}{l}\text { L-PM } \\
\text { Low-skill unemployed } \\
\left(U_{4}\right)\end{array}$ & $\begin{array}{l}\text { L-MI } \\
\text { Low-skill unemployed } \\
\left(U_{4}\right)\end{array}$ \\
\hline$D$-heterogeneity & $\begin{array}{l}\text { D-PM } \\
\text { Inactive individuals } \\
(v / r)\end{array}$ & $\begin{array}{l}\text { D-MI } \\
\text { Inactive individuals } \\
\left(\left(v+z_{u}\right) / r\right)\end{array}$ \\
\hline
\end{tabular}

\footnotetext{
${ }^{\text {a }}$ Transfers to the inactive are set to 0 whereas unemployment benefits vary in simulations (along the $y$-axis in Figs. 2 and 3)

${ }^{\mathrm{b}}$ Transfers to the inactive are identical to unemployment benefits. Both vary together in simulations (along the $y$-axis in Figs. 4 and 5)
}

In our analysis of reform policies, we take account of the problem of imperfect monitoring of job search effort and of the government's uncertainty about the type of heterogeneity that governs participation behavior. We do this by considering four different model versions that are distinguished along two dimensions (see Table 3). On the one hand, heterogeneity is modeled either as varying preference for leisure ( $L$-heterogeneity) or as different degrees of disability of work ( $D$-heterogeneity). On the other hand, we assume that job search monitoring is either perfect (PM) or impossible (MI). In Table 3, we show the acronyms of the four model versions and indicate the identity and utility level of the least well-off individual. The latter is determinant for the Rawlsian case of the SWF and will help us to interpret the simulation results for $\epsilon=\infty$.

For the reasons outlined above, our preferred reform candidate is the introduction of in-work benefits, keeping the unemployment benefit at its initial level. The marginal tax rate is determined by the balanced budget constraint of the government. In the context of our calibrated model, this reform will turn out to be the only one that is able to increase (or to not decrease) social welfare for all SWFs in the class that we consider, and for all model versions that we consider. In a first step, we explore this question by depicting social indifference curves in the space $\left(z_{w}, z_{u}\right)$ for different degrees of inequality-aversion and for all four versions of the model (see Figs. 2 to 5). Note that $z_{n}$ varies together with $z_{u}$ in model versions where job search monitoring is impossible (MI); it is set to zero if monitoring is perfect (PM). The initial situation of the economy is indicated by a black square and the direction of our preferred reform policy is depicted by an arrow.

Some intuition can be gained by considering first a simplified model with exogenous participation. In this case, the tax system cannot distort the participation decision (by assumption) and condition (21) alone determines maximum economic efficiency. Panel (a) of Fig. 1 depicts indifference curves of a utilitarian SWF that is 


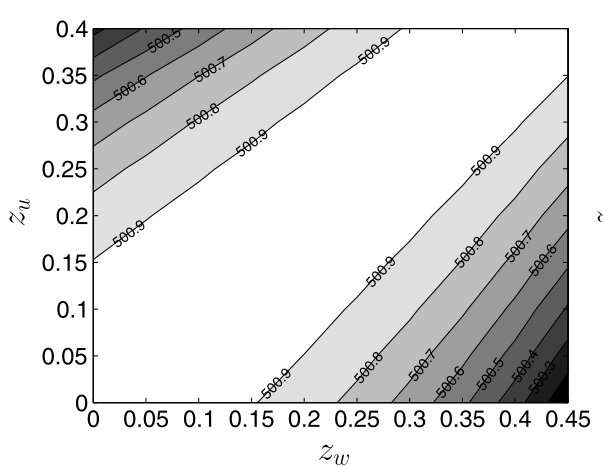

(a) $\epsilon=0$

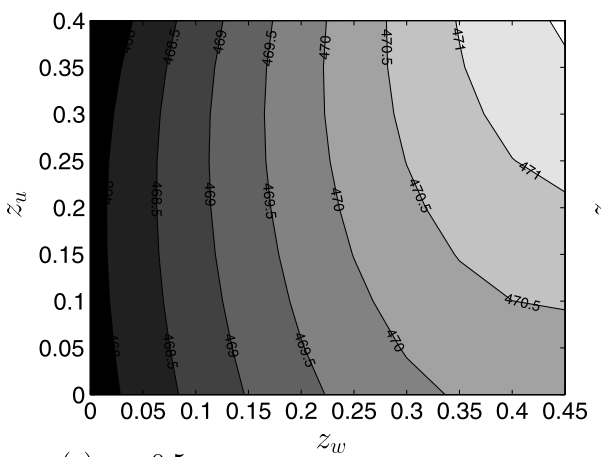

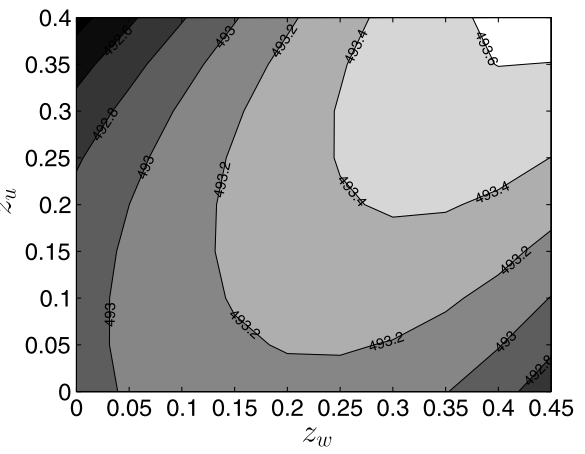

(b) $\epsilon=0.1$

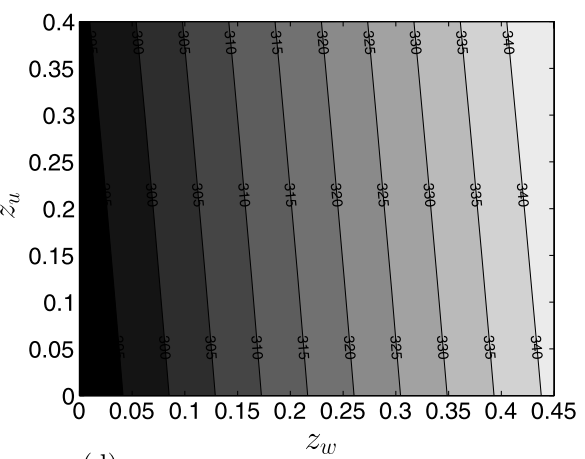

(d) $\epsilon=\infty$

Fig. 1 Social welfare contours as a function of $z_{w}$ and $z_{u}$, for different values of inequality aversion: model version L-PM with exogenous labor supply

insensitive to inequality $(\epsilon=0){ }^{22}$ The "ridge" of the SWF along the diagonal confirms that maximum efficiency is reached when $z_{u}=z_{w}$, regardless of the level of benefits. A government whose SWF exhibits inequality aversion $(\epsilon>0)$ will prefer to choose higher benefit levels (as long as they are identical) since higher benefit levels imply a higher marginal tax rate and therefore a more progressive tax system. This is clearly illustrated by the other panels of Fig. 1, which show that social welfare increases in the direction of the upper right corner. Therefore, the optimal policy (which second-order dominates all other policies) consists in letting the marginal tax rate $\tau /(1+\tau)$ go to 1 . In that case, utilities of all individuals are equalized, even between the employed and the unemployed ( $W_{i}-U_{i}$ tends to 0 , see footnote 11). This result shows that it is crucial to take the participation decision into account in order to get meaningful results.

Now turn to the model with endogenous participation. Social indifference curves of the four model versions are depicted in Figs. 2-5. Consider first the results with respect to economic efficiency (utilitarian SWF, shown in panel (a) of Figs. 2-5).

\footnotetext{
${ }^{22}$ These social indifference curves were calculated using version L-PM of the model. Results with version L-MI are identical for the SWF with $\epsilon=0$ and are available on request.
} 


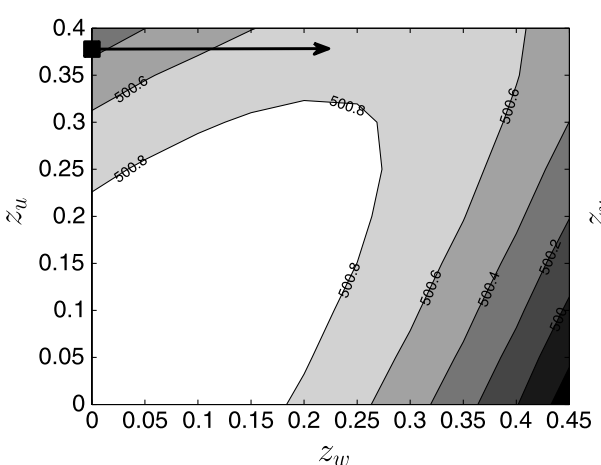

(a) $\epsilon=0$

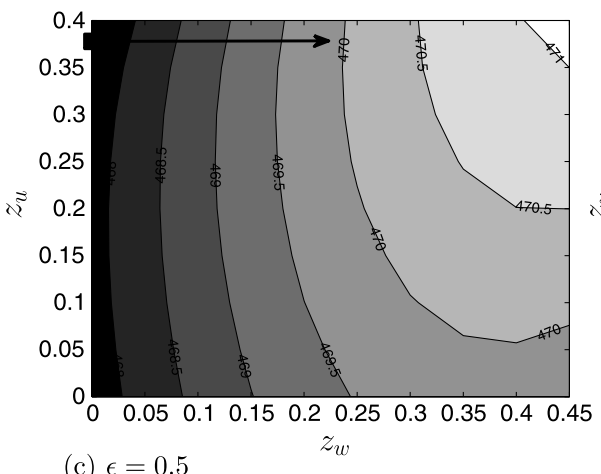

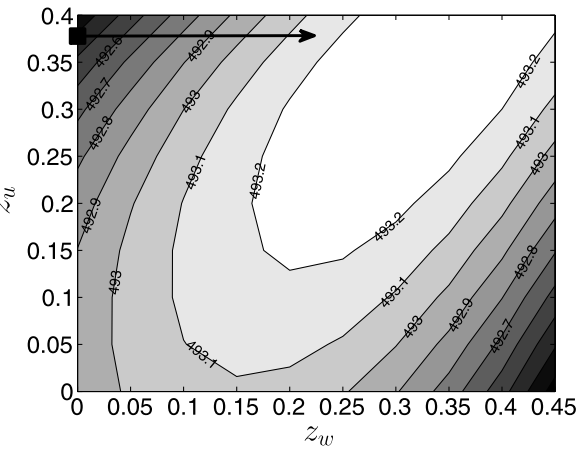

(b) $\epsilon=0.1$

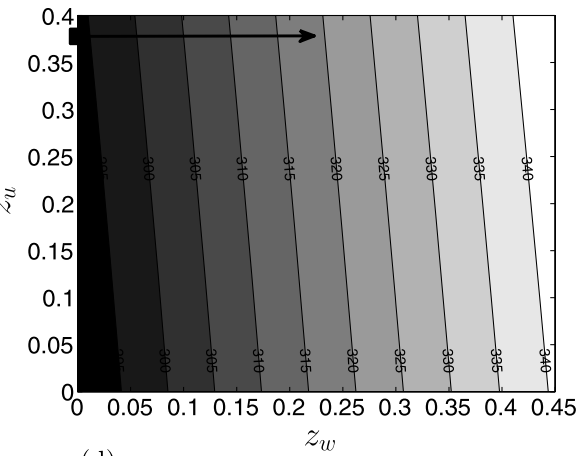

(d) $\epsilon=\infty$

Fig. 2 Social welfare contours as a function of $z_{w}$ and $z_{u}$, for different values of inequality aversion: model version L-PM

In all model versions, maximum efficiency is attained for $z_{u}=z_{w}=0$. For model versions L-PM and D-PM (Figs. 2 and 3), this might seem surprising in the light of the theoretical result obtained above for the model with perfect job search monitoring. The main reason for this outcome is obviously the fact that we impose a unique marginal tax rate instead of the optimal structure that is decreasing with skill. The efficiency cost of redistribution seems to be rather low, however, since the level of social welfare decreases very slowly when traveling from the origin toward the upper right corner, along the diagonal where $z_{u}=z_{w}$. This is confirmed by the fact that the optimal $z_{u}$ and $z_{w}$ grow very rapidly when one considers SWFs with increasing inequality aversion (see panels (b) to (d) of Figs. 2 and 3). For $\epsilon=0.1$, optimal social welfare is attained for approximately $z_{u}=z_{w}=0.3$, corresponding to $\tau=0.42$ (equivalent to a marginal tax rate of 0.29 levied on pretax income). For $\epsilon=0.5$, the optimal $z_{w}$ obviously exceeds 0.4 , but the condition $z_{u}=z_{w}$ should still hold approximately at the social welfare optimum.

To understand the results for the Rawlsian SWF (panel (d)), it is important to see that the degree of redistribution increases much more when moving from left to right (by increasing $z_{w}$ ) than by moving from the bottom to the top (by increasing $z_{u}$ ). The reason is that an increase of in-work benefits concerns a large majority of the population and increases marginal tax rates much more than an increase in the un- 


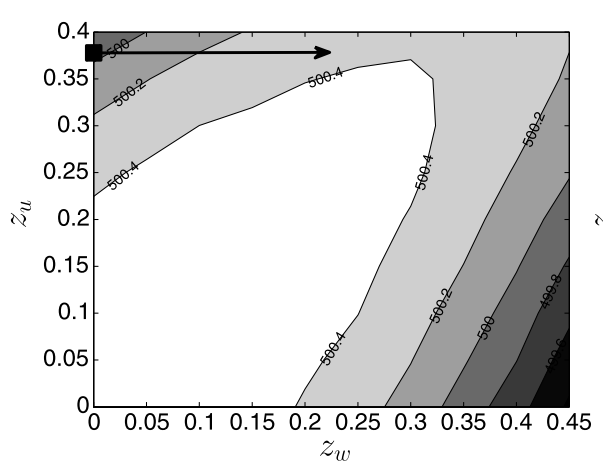

(a) $\epsilon=0$

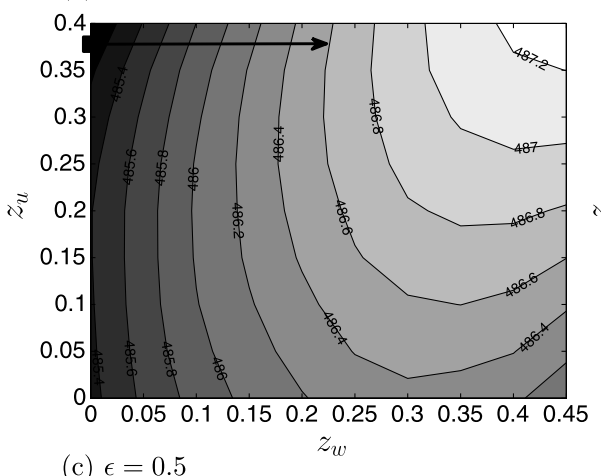

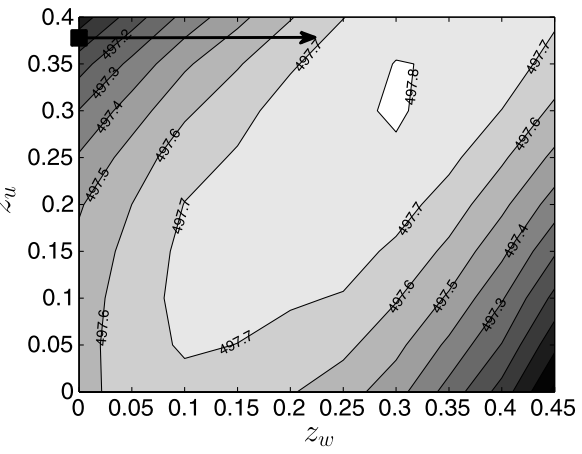

(b) $\epsilon=0.1$

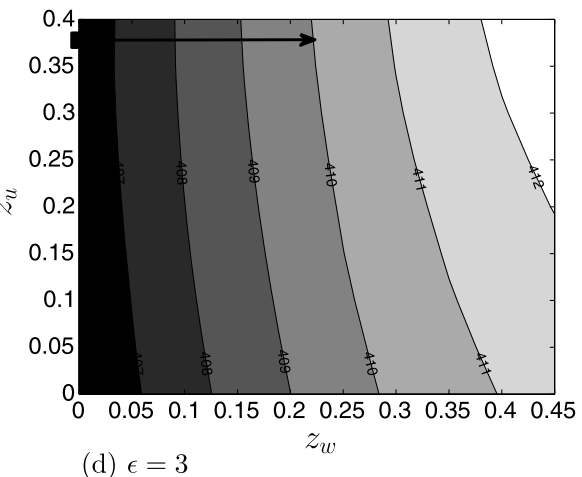

Fig. 3 Social welfare contours as a function of $z_{w}$ and $z_{u}$, for different values of inequality aversion: model version D-PM

employment benefit (marginal tax rates are close to $44 \%$ at the lower right corner of Figs. 2 and 3, but only equal to $1.5 \%$ at the upper left corner). The Rawlsian SWF prefers a more progressive tax system as can be obtained by increasing $z_{w}$.

For the model versions where search monitoring is impossible (L-MI and D-MI, Figs. 4 and 5), the efficiency cost of increasing the unemployment benefit (and simultaneously the transfer to the inactive since $z_{n}=z_{u}$ ) is higher due to the fact that the higher average tax rates, required to finance the transfers to the inactive, distort the participation decision to a greater degree. With an inequality-averse SWF, the results depend greatly on the type of preference heterogeneity that is assumed. With $L$-heterogeneity (Fig. 4), the least well-off individual is a low-skilled unemployed. Somehow paradoxically, he benefits much more from the introduction of an in-work benefit (the expected time to find a job is 3 months) than from the increase in unemployment benefits, which are also paid to the inactive (and which he contributes to finance by his taxes). Therefore, in model version L-MI, the Rawlsian SWF favors a high degree of redistribution, but only among the labor force by increasing simultaneously $z_{w}$ and the marginal tax rate.

If preference heterogeneity is interpreted as capturing different degrees of work disability ( $D$-heterogeneity, Fig. 5), the inactive are the least well-off individuals in the economy. Therefore, their utility level will count more in the SWF if the govern- 


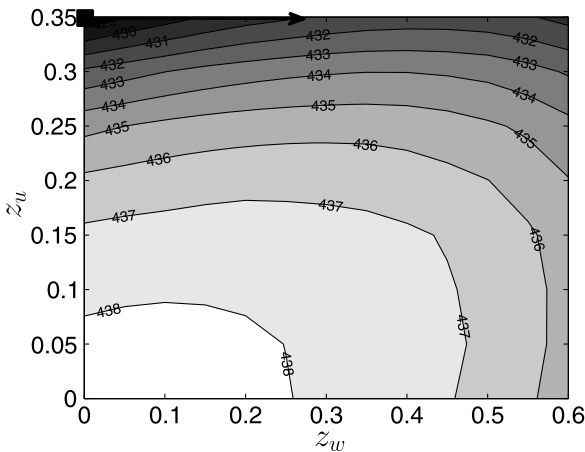

(a) $\epsilon=0$

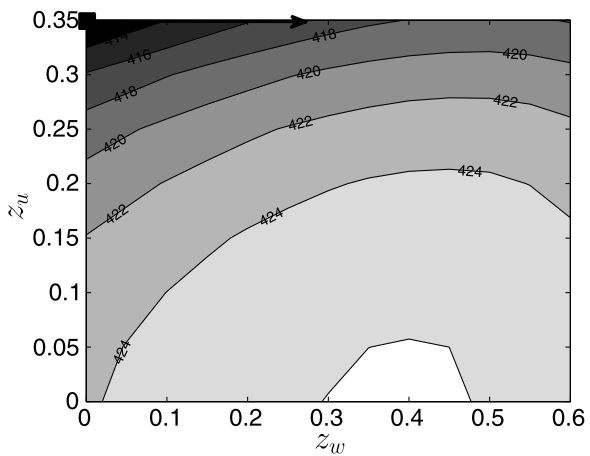

(c) $\epsilon=0.5$

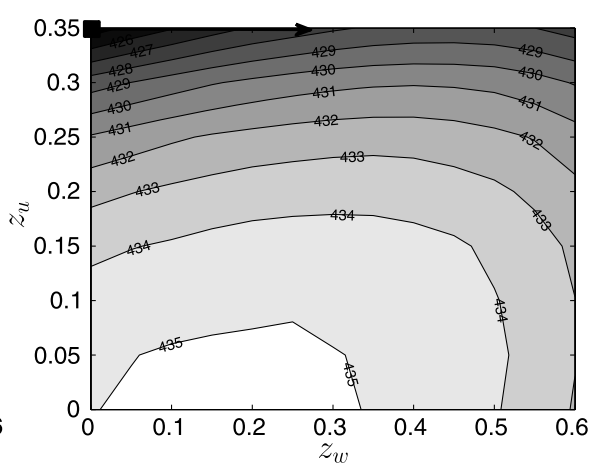

(b) $\epsilon=0.1$

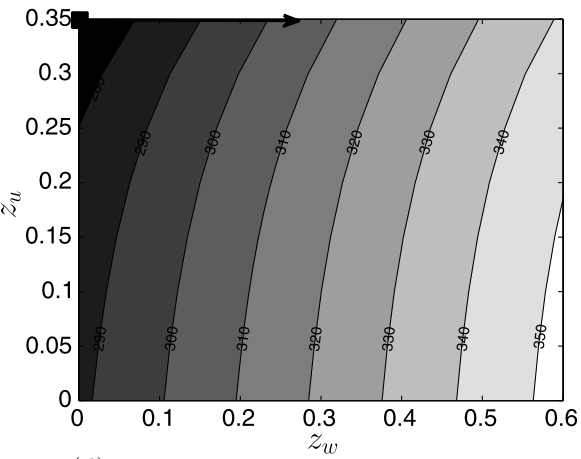

(d) $\epsilon=\infty$

Fig. 4 Social welfare contours as a function of $z_{w}$ and $z_{u}$, for different values of inequality aversion: model version $\mathbf{L}-\mathbf{M I}$

ment is inequality-averse and transfers to individuals without a job are more highly valued than in the $L$-heterogeneity case. For the Rawlsian SWF, the result is straightforward: only an increase in $z_{u}$ improves the well-being of the least well-off since their intertemporal utility is given by $\left(v+z_{u}\right) / r$. This result is the reason why reform policies that start from the initial situation depicted by a black square must not decrease unemployment benefits since this would unambiguously decrease social welfare according to the Rawlsian SWF.

It is interesting to note that the type of preference heterogeneity matters only if search behavior cannot be monitored. In the opposite case, the two model versions L-PM and D-PM yield almost identical results (Figs. 2 and 3). This result shows that the assumptions about heterogeneity matter when the individuals outside the labor force are concerned by transfer policies.

To sum up, all our model versions and SWF variants arrive at the conclusion that the introduction of in-work benefits seems a promising reform candidate. Moreover, in the limits of our exercise where marginal tax rates are constant, it seems to be the only reform candidate. Indeed, starting from the initial situation (depicted by the black square), the only direction in which social welfare increases in all panels of Figs. $2-5$ is to the right (as indicated by the arrow). 


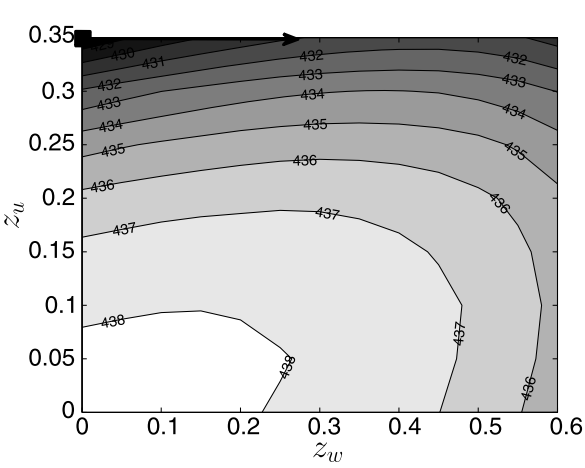

(a) $\epsilon=0$

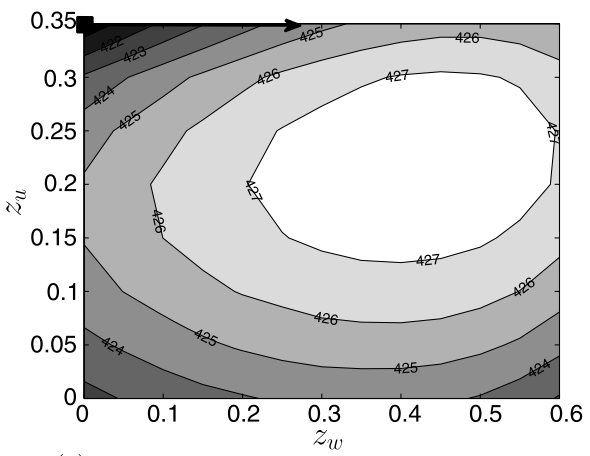

(c) $\epsilon=0.5$

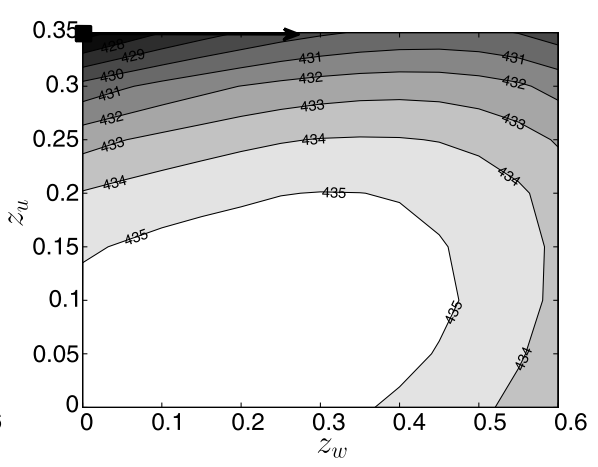

(b) $\epsilon=0.1$

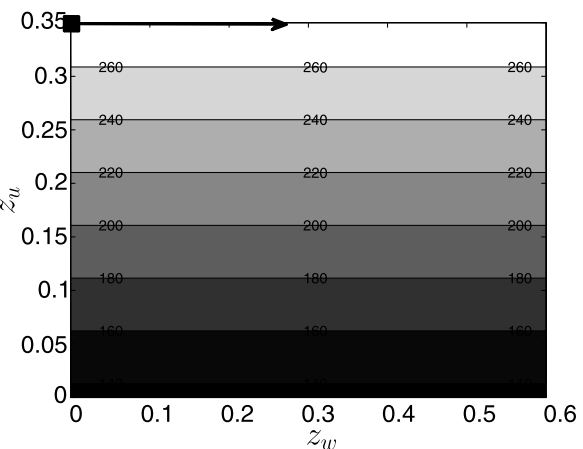

(d) $\epsilon=\infty$

Fig. 5 Social welfare contours as a function of $z_{w}$ and $z_{u}$, for different values of inequality aversion: model version D-MI

\subsection{Generalized Lorenz dominance}

Having identified the introduction of in-work benefits as a promising candidate for reform, we proceed in this section to a more formal check whether such a measure would satisfy not only necessary, but also sufficient conditions for being socially desirable. We will also explore whether any level of in-work benefits (up to the level of unemployment assistance) would fulfill the requirements of a socially desirable reform.

The ordinal approach can be made operational by applying Shorrocks' (1983) Theorem 2. This theorem states that a reform would increase social welfare according to any SWF satisfying the criteria of Pareto, anonymity, and the principle of transfers if and only if the post-reform Generalized Lorenz (GL) curve dominates the pre-reform GL-curve. ${ }^{23}$ The criterion of GL-dominance ensures therefore that the desirability of a reform would be judged in an unanimous way by observers whose ethical preferences can be described by any SWF satisfying the three criteria given above.

\footnotetext{
${ }^{23}$ Generalized Lorenz dominance is equivalent to second-order stochastic dominance (Thistle 1989). See also Sen (1997, p. 132-138).
} 
The preceding discussion suggests that an increase in $z_{w}$ would be a promising reform candidate, with $z_{u}$ remaining unchanged. With linear taxation and a balanced government budget, such a reform increases the progressivity of the tax system and implies more redistribution. From the point of view of economic efficiency, there are two counterbalancing effects: labor market tightness evolves toward greater efficiency, but more redistribution among skill categories biases participation decisions in an inefficient manner (the participation rate increases for the low-skilled, and decreases for the high-skilled). The simulations described above suggest that in the Swiss case, the former effect dominates the latter.

In order to check formally for social welfare dominance, we compare generalized Lorenz curves of the pre- and post-reform situations. Recall that the generalized Lorenz curve (Shorrocks 1983) can be obtained from the ordinary Lorenz curve by multiplying cumulated income shares (measured on the $y$-axis) by mean income. Our two necessary conditions for a reform to improve social welfare have simple interpretations in the context of the GL curves. First, the vertical distance between the two curves at the far right indicates the difference between mean incomes in the post- and pre-reform situations. Second, the difference between slopes at the origin of the two GL curves indicates whether the group of individuals with the lowest utility level fare better after the reform. Therefore, the necessary conditions for SW (or GL) dominance are that the post-reform GL curve starts out with a greater (or identical) slope than the pre-reform curve and that it arrives at a higher (or identical) level at the right end.

To make small differences more visible, Fig. 6 shows the vertical distance between two post-reform GL curves (partial reform with $z_{w}=0.1$; full reform with $z_{w}=z_{u}$ ) and the pre-reform GL curve (base case with $z_{u}=0.4$ and $z_{w}=0$ ) for all four model versions. In all cases, the reform produces an efficiency gain since the difference between post- and pre-reform GL curves ends up at a positive level. The efficiency gain is greater in the model versions where job search monitoring is impossible (L-MI and D-MI).

In the model version L-PM, the partial reform dominates the pre-reform situation, whereas this is not the case for the full reform (the GL curves intersect twice above the 90th percentile). How can this result be explained? As indicated above, the parallel increase of $z_{w}$ and $\tau$ increases the progressivity of the tax system and leads to redistribution from high-skill workers to low-skill workers. The adverse distributional effects seem to become important with the full reform and high-skill workers lose more than low-skill workers gain. Only the gains of entrepreneurs ensure that the sum of individual utilities increases with the full reform. It should be noted that this result depends on our assumptions on firm ownership (entrepreneurs form a separate population group and are initially "richer" than workers) and on tax structure (firm profits are not taxed). Alternative assumptions might lead to the conclusion that even the full reform dominates the initial situation according to the GL criterion.

One can therefore conclude from the preceding discussion that the introduction of in-work benefits (with $z_{w}$ lower than $z_{u}$ ) is a socially desirable reform in the sense that it is preferred to the current situation in Switzerland by any observer using a social welfare criterion embodying some degree of inequality aversion. 


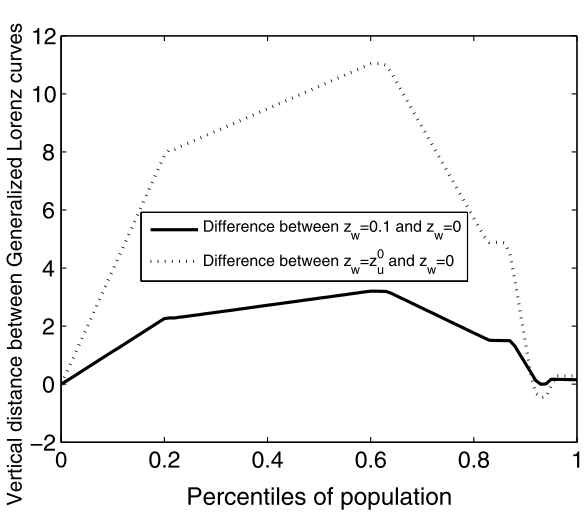

(a) model version L-PM

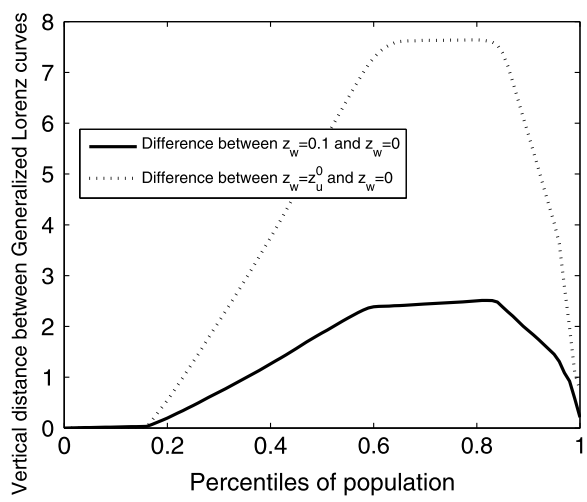

(c) model version D-PM

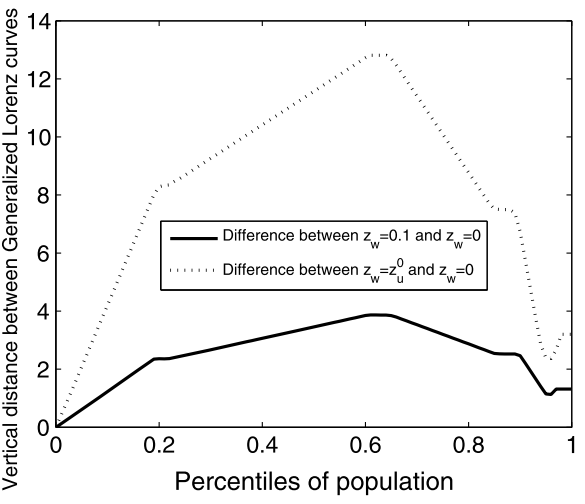

(b) model version L-MI

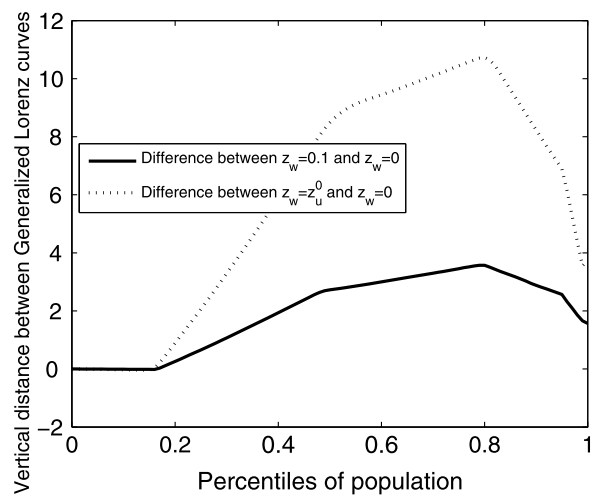

(d) model version D-MI

Fig. 6 Generalized Lorenz dominance: impact of in-work benefits in different model versions

\section{Conclusions}

In this paper, we search for socially desirable tax-benefit reforms by adopting an ordinal approach to social welfare comparisons: a post-reform situation is preferred to the current situation if social welfare is improved according to an entire class of social welfare functions. This approach enables us to identify reforms that could be agreed upon by observers with different value judgments as long as these satisfy some widely accepted criteria.

We use a model with endogenous labor supply and unemployment where more redistribution does not necessarily come at the expense of economic efficiency. Starting from the current (nonoptimal) situation, there is scope for enhancing efficiency without increasing inequality and worsening the situation of the least well-off. Using a calibrated model for Switzerland, we show that the introduction of in-work benefits would be a socially desirable reform in the sense that it would be unanimously preferred to the current situation according to all social welfare functions based on the criteria of Pareto, anonymity, and the principle of transfers. 
It should be emphasized that this unanimity is obtained for four versions of the model, accounting for the possibility that job search effort cannot be monitored and that preference heterogeneity can take two different forms. This result is all the more remarkable as the two types of preference heterogeneity and the two polar cases of search monitoring lead to quite different shapes of the social welfare function.

The analysis of these reform policies could be refined in future work by extending our framework in two directions. First, the choice of work hours could be endogenized in the model. In a labor supply setting without search frictions, Saez (2002) shows that the optimal tax schedule is closer to a negative income tax if labor market responses are concentrated along the intensive (hours) margin. It remains to be seen whether these results carries over to a model with involuntary unemployment.

Second, the existence of a segmented labor market might change the conclusions with respect to socially desirable reforms. Acemoglu (2001) uses a search-matching model where "good" and "bad" jobs are created in equilibrium because of different (sunk) capital costs. He shows that the composition of jobs is inefficiently biased toward low-wage jobs because of hold-up problems. In this context, the reduction in the average tax rates for low incomes implied by in-work benefits is likely to shift the composition of low-skill employment even further toward the "bad jobs," leading to an efficiency loss. The exact implications for the design of tax-benefit reforms is left for future research.

Acknowledgements We thank Bruno van der Linden, Jaime de Melo, and two anonymous referees for very helpful comments on earlier versions.

\section{Appendix A: Economic efficiency: optimality conditions}

According to the utilitarian criterion, aggregate welfare $\Psi$ (at time $t=0$ ) is defined as the sum of individual utilities:

$$
\Psi=\sum_{i} s_{i}\left[\left(1-\pi_{i}\right) \bar{N}_{i}+\left(\pi_{i}-\ell_{i}(0)\right) U_{i}+\ell_{i}(0)\left(W_{i}+J_{i}\right)\right],
$$

where $\pi_{i}=H\left(\xi_{i}\right), \ell_{i}(0)$ is the initial employment rate and $\bar{N}_{i}=\int_{\xi_{i}}^{\infty} x H^{\prime}(x) \mathrm{d} x /$ $\left(1-\pi_{i}\right)+z_{n}$ is average utility of inactive individuals. It can be shown that (A.1) is equal to

$$
\Psi=\sum_{i} s_{i} \int_{0}^{\infty}\left\{\int_{\xi_{i}}^{\infty} x H^{\prime}(x) \mathrm{d} x+\ell_{i}(t) p_{i}-\left(\pi_{i}-\ell_{i}(t)\right) p_{i} c \theta_{i}\right\} \mathrm{e}^{-r t} \mathrm{~d} t
$$

where $\ell_{i}(t)$ evolves according to (1). The initial employment rates $\ell_{i}(0)$ are fixed and the problem of efficiency maximization consists in maximizing $\Psi$ subject to

$$
\dot{\ell}_{i}(t)=\theta_{i} m\left(\theta_{i}\right) \pi_{i}-\left[q+\theta_{i} m\left(\theta_{i}\right)\right] \ell_{i}(t), \quad \pi_{i}=H\left(\xi_{i}\right), \quad \ell_{i}(0)=\ell_{i}^{0} .
$$


Consider first the optimal level of labor market tightness, denoted by $\hat{\theta}_{i}$. According to the necessary conditions of the maximum principle, $\hat{\theta}_{i}$ is the solution of ${ }^{24}$

$$
\left[r+q+\theta_{i} m\left(\theta_{i}\right)\right] c /\left(1+\theta_{i} c\right)=m\left(\theta_{i}\right)\left[1-\eta\left(\theta_{i}\right)\right]
$$

where $\eta\left(\theta_{i}\right)=\left|\theta_{i} m^{\prime}\left(\theta_{i}\right) / m\left(\theta_{i}\right)\right|$ is the absolute value of the elasticity of $m\left(\theta_{i}\right)$.

What policies can the government use to attain maximum efficiency? In the decentralized equilibrium, $\theta_{i}$ is determined by Eq. (16). Combining this equation with the optimality condition (A.4) and using (9) yields Eq. (21) in the main text. ${ }^{25}$

Now turn to the optimal choice of labor market participation, denoted by $\hat{\pi}_{i}=$ $H\left(\hat{\xi}_{i}\right)$. The optimal reservation level of the leisure parameter is given by $\hat{\xi}_{i}=g_{i}\left(\hat{\theta}_{i}\right)$, where $g_{i}$ is derived from the following first-order condition, obtained by maximizing the Hamiltonian with respect to $\xi_{i}$ :

$$
\xi_{i}=\frac{m\left(\theta_{i}\right)-(r+q) c}{r+q+\theta_{i} m\left(\theta_{i}\right)} p_{i} \theta_{i} \equiv g_{i}\left(\theta_{i}\right) .
$$

What policies are compatible with optimal participation rates? Combining (A.5) with the job creation condition (15) yields

$$
\xi_{i}=\frac{\theta_{i} m\left(\theta_{i}\right)}{r+q+\theta_{i} m\left(\theta_{i}\right)} w_{i}(1+\tau) .
$$

Comparison of (A.6) with the determination of $\xi_{i}$ in the decentralized equilibrium (11) leads to the following condition:

$$
\tau w_{i}=z_{w}-z_{n}+\frac{r+q}{\theta_{i} m\left(\theta_{i}\right)}\left(z_{u}-z_{n}\right) .
$$

Equation (A.7) leads to the conclusion that a laissez-faire policy without government intervention ensures maximum efficiency with respect to the participation decision. As there are no externalities involved, this does not come as a surprise. A more interesting question is whether there exist other policies that can ensure an efficient outcome. To address this question more clearly, the government's budget constraint has to be taken into account. Substituting (A.7) into the intertemporal budget constraint (14) yields condition (22) in the main text.

\section{References}

Abul Naga, R., Kolodziejczyk, C., \& Müller, T. (2008). The redistributive impact of alternative income maintenance schemes: a microsimulation study using Swiss data. Review of Income and Wealth, 54(2), 193-219.

${ }^{24}$ Condition (A.4) is implied by the following conditions of the maximum principle: $\partial H_{c} / \partial \theta_{i}=0$ and $\dot{\mu}_{i}-r \mu_{i}=-\partial H_{c} / \partial \ell_{i}$ where $H_{c}$ is the current-value Hamiltonian and $\mu$ the multiplier associated with (A.3). Close inspection of necessary conditions reveals that $\dot{\mu}_{i}=0$ since $\mu_{i}$ jumps to its steady state value.

${ }^{25}$ Note that (16) can be written as

$$
\frac{r+q+\theta_{i} m\left(\theta_{i}\right)}{1+\theta_{i} c} c=(1-\beta)\left(1-\frac{(1+\tau)\left(z_{u}-z_{w}\right)}{p_{i}\left(1+\theta_{i} c\right)}\right) m\left(\theta_{i}\right) .
$$


Acemoglu, D. (2001). Good jobs versus bad jobs. Journal of Labor Economics, 19, 1-21.

Atkinson, A. B. (1970). On the measurement of inequality. Journal of Economic Theory, 2, 244-263.

Beaudry, P., Blackorby, C., \& Szalay, D. (2009). Taxes and employment subsidies in optimal redistribution programs. American Economic Review, 99, 216-242.

Blundell, R., \& MaCurdy, T. (1999). Labor supply: a review of alternative approach. In O. Ashenfelter \& D. Card (Eds.), Handbook of labor economics (Vol. 3A). Amsterdam: Elsevier.

Blundell, R., Duncan, A., McCrae, J., \& Meghir, C. (2000). The labour market impact of the working families' tax credit. Fiscal Studies, 21, 75-104.

Boone, J., \& Bovenberg, L. (2002). Optimal labour taxation and search. Journal of Public Economics, 85, 53-97.

Boone, J., \& Bovenberg, L. (2004). The optimal taxation of unskilled labor with job search and social assistance. Journal of Public Economics, 88, 2227-2258.

Choné, P., \& Laroque, G. (2005). Optimal incentives for labor force participation. Journal of Public Economics, 89, 395-425.

Choné, P., \& Laroque, G. (2010). Negative marginal tax rates and heterogeneity. American Economic Review, 100, 2532-2547.

Choné, P., \& Laroque, G. (2011). Optimal taxation in the extensive model. Journal of Economic Theory, $146,425-453$.

Cuff, K. (2000). Optimality of workfare with heterogeneous preferences. Canadian Journal of Economics, $33,149-174$.

Diamond, P. A. (1980). Income taxation with fixed hours of work. Journal of Public Economics, 13(1), 101-110.

Feldstein, M. (1976). On the theory of tax reform. Journal of Public Economics, 6, 77-104.

Flückiger, Y., \& Vassiliev, A. (2002). Les raisons des différences de chômage entre Genève et le reste de la Suisse. Revue suisse d'économie et de statistique, 138, 387-410.

Fortin, B., Truchon, M., \& Beauséjour, L. (1993). On reforming the welfare system: workfare meets the negative income tax. Journal of Public Economics, 51, 119-151.

Gerfin, M., \& Leu, R. E. (2007). Evaluating the cost-effectiveness of in-work benefits: a simulation study for Switzerland. German Economic Review, 8, 447-467.

Guesnerie, R. (1977). On the direction of tax reform. Journal of Public Economics, 7, 179-202. 1977.

Hosios, A. J. (1990). On the efficiency of the matching and related models of search and unemployment. Review of Economic Studies, 57, 279-298.

Hungerbühler, M., Lehmann, E., Parmentier, A., \& Van der Linden, B. (2006). Optimal redistributive taxation in a search equilibrium model. Review of Economic Studies, 73, 743-767.

Immervoll, H., Kleven, H., Kreiner, C. T., \& Saez, E. (2007). Welfare reforms in European countries: a microsimulation analysis. Economic Journal, 117, 1-44.

Lehmann, E. (2003). Evaluation de la mise en place d'un système d'allocation universelle en présence de qualifications hétérogènes. Economie et prévision, 157, 31-50.

Lehmann, E., Parmentier, A., \& Van der Linden, B. (2011). Optimal income taxation with endogenous participation and search unemployment. Journal of Public Economics, 95, 1523-1537.

Meghir, C., \& Phillips, D. (2008). Labour supply and taxes. IZA Discussion Paper 3405.

Mirrlees, J. A. (1971). An exploration in the theory of optimal taxation. Review of Economic Studies, 38, 175-208.

Moene, E. (1997). Competitive search equilibrium. Journal of Political Economy, 105, 385-411.

Moffitt, R. (2003). The negative income tax and the evolution of US welfare policy. Journal of Economic Perspectives, 17, 119-140.

Mortensen, D., \& Pissarides, C. A. (1999). New developments in models of search in the labor market. In O. Ashenfelter \& D. Card (Eds.), Handbook of labor economics (Vol. 3B). Amsterdam: Elsevier.

OFS (Office fédéral de la statistique) (1999). Enquête suisse sur le niveau et la structure des salaires 1998, Neuchâtel.

OFS (Office fédéral de la statistique) (2000). Statistiques des places vacantes, Emploi et vie active, Neuchâtel.

OFS (Office fédéral de la statistique) (2001a). Indicateurs du marché du travail 2001, Neuchâtel.

OFS (Office fédéral de la statistique) (2001b). L'enquête suisse sur la population active (ESPA) en 2001, Neuchâtel.

Petrongolo, B., \& Pissarides, C. A. (2001). Looking in the black box: a survey of the matching function. Journal of Economic Literature, 39, 390-431.

Pissarides, C. A. (1998). The impact of employment tax cuts on unemployment and wages; The role of unemployment benefits and tax structure. European Economic Review, 42, 155-183. 
Pissarides, C. A. (2000). Equilibrium unemployment theory (2nd ed.). Cambridge: MIT Press.

Saez, E. (2002). Optimal income transfer programs: intensive versus extensive labor supply reponses. Quarterly Journal of Economics, 117, 1039-1072.

Sen, A. (1997) On economic inequality. Oxford: Clarendon Press. Expanded edition with a substantial annexe by J.E. Foster and A. Sen.

Shorrocks, A. F. (1983). Ranking income distributions. Economica, 50, 3-17.

Sørensen, P. B. (1999). Optimal tax progressivity in imperfect labour markets. Labour Economics, 6, 435452.

Strand, J. (2002). Effects of progressive taxes under decentralized bargaining and heterogeneous labor. International Tax and Public Finance, 9, 195-210.

Thistle, P. D. (1989). Ranking distributions with generalized Lorenz curves. Southern Economic Journal, $56,1-12$.

Van der Linden, B. (2002). Is basic income a cure for unemployment in unionized economies? Annales d'économie et de Statistique, 66, 81-105.

Van der Linden, B. (2004). Active citizen's income, unconditional income and participation under imperfect competition: a normative analysis. Oxford Economic Papers, 56, 98-117.

Weymark, J. A. (1981). Undominated directions of tax reform. Journal of Public Economics, 16, 343-369. 